San Jose State University

SJSU ScholarWorks

Master's Projects

Master's Theses and Graduate Research

$1-1-1998$

\title{
The Effectiveness Of A Strength Training Program On Extremity Strength, Flexibility, And Balance Of Elderly Women
}

Patricia L. Murphy

San Jose State University

Follow this and additional works at: https://scholarworks.sjsu.edu/etd_projects

Part of the Geriatric Nursing Commons

\section{Recommended Citation}

Murphy, Patricia L., "The Effectiveness Of A Strength Training Program On Extremity Strength, Flexibility, And Balance Of Elderly Women" (1998). Master's Projects. 874.

DOI: https://doi.org/10.31979/etd.tesk-d2td

https://scholarworks.sjsu.edu/etd_projects/874

This Master's Project is brought to you for free and open access by the Master's Theses and Graduate Research at SJSU ScholarWorks. It has been accepted for inclusion in Master's Projects by an authorized administrator of SJSU ScholarWorks. For more information, please contact scholarworks@sjsu.edu. 
Running head: EFFECTIVENESS OF STRENGTH TRAINING

\author{
The Effectiveness Of A Strength Training \\ Program On Extremity Strength, Flexibility, \\ And Balance Of Elderly Women \\ Patricia L. Murphy, BSN, RN \\ San Jose State University
}

Author Note

Patricia L. Murphy, BSN, RN, Department of Nursing.

This study was presented to the University as a Master's Program

Project and does not reflect the views or opinions of the University or any of its affiliates.

I deeply appreciate and acknowledge the work of both Colleen Saylor, Ph.D. and Bobbye Gorenberg, D.N.Sc. whose vigilant guidance and encouragement as my primary and secondary readers, respectively, on this project saw me through many confusing and frustrating days of preparation.

Correspondence concerning this article should be addressed to Patricia L. Murphy, BSN, RN, 


\begin{abstract}
This quasi-experimental study, partially replicating that of Nelson and Wernick (1997), compares balance, flexibility, and extremity strength before and after an 8-week weight-bearing exercise class. Six women, aged 69 to 85 , used 1-5 pound wrist weights and ankle weights up to 10 pounds. Preand post-exercise measurements of biceps curls, seated leg lifts with weights, one leg stand, and seated stretches were gathered. Results showed improvement in every category, with the greatest improvement $(41.6 \%)$ in balance and the least $(8.3 \%)$ in trunk flexibility. Nursing is uniquely positioned to assist this population by promoting, developing, and implementing such exercise programs.
\end{abstract}




\author{
The Effectiveness of a \\ Strength Training Program on \\ Extremity Strength, Flexibility and \\ Balance of Elderly Women
}

Introduction

The U.S. Department of the Census (1997) has projected that $20 \%$ of the U.S. population, or 79 million individuals, will be aged 65 or older by the year 2030. This is compared to 1995 figures of 34 million, or $13 \%$ of population. While technology has extended human longevity, the quality of life has not necessarily been improved, as reflected in the assertion that "exertion has been engineered out of many occupations and automation has taken over recreational activities" (Jones \& Jones, 1997, p. 47).

According to published reports, the U.S. Department of Health and Human Services (1995) projected that approximately 250,000 deaths per year in the United States could be attributed to a lack of physical activity. It is generally believed that as an average American advances in age, there is a corresponding decline in physical activity (Kohrt, Snead, Slatopolsky, \& Birge, 1995). This trend implies that the decline in physical activity is a major contributing factor in a decline in quality of life as people age. Only within the decade of the 90 s have researchers begun serious studies designed to look at how exercise affects the aging body and how those effects influence quality of life.

Among the natural consequences of aging, a decline in strength, flexibility, and balance play a vital role in continued physical well being. As falls and the consequences of those falls have been shown to increase both 
morbidity and mortality in the elderly, the prevention of those falls "will become increasingly important for preserving the health and independence of older women" (Judge, Lindsey, Underwood, \& Winsemius, 1993, p. 254). The propensity for women, especially, to be affected by these three indicators has lead to the increased research during the past decade. This research overwhelmingly supports the conclusion that the consequence of natural decline in these three areas can not only be mitigated, but in most cases reversed, by the inclusion of a regular program of physical activity in women's daily lives, including weight-bearing exercise (Nelson \& Wernick, 1997).

One of the most telling findings related to the promotion of physical activity among elderly women was Mistressa and Jones' 1996 study (cited in Jones \& Jones, 1997). The focus of the study was on older women's perceptions of their risk for both stroke and cardiovascular disease. While $97 \%$ of older women perceived exercise to be important in disease prevention, and $73 \%$ reported exercising at least twice a week, $45 \%$ of the sample reported never to have been advised to exercise by their health care providers.

One way to change this apparent lack of emphasis on physical activity is for health care providers to begin prescribing exercise to their patients (Jones \& Jones, 1997). This prescription to exercise should not be done casually, as if by afterthought, but rather in the same manner as when recommending any prescription medication. Providers could utilize this opportunity to emphasize the importance of regular physical activity with their elderly patients by formally writing a prescription for exercise, outlining the frequency, intensity, timing, and duration of physical activity in this form. Only this type of focused, serious approach has the potential to capture 
patients' attention and motivate them to take action in support of their provider's recommendation to use exercise to enhance their physical well being.

This project describes an exercise intervention program for elderly women, designed to improve their strength, flexibility, and balance. The question asked was whether regular participation in a strength training exercise program would improve pre-exercise measurements of strength, balance, and flexibility of women over the age of 65 . The long-term goal of such a program would be to give women a proven tool to use to reduce their risk of fracture, isolation, incapacity, and dependence as they age.

Conceptual Framework

The conceptual framework for this research project is the Health Promotion Model developed by Pender (1987). This model focuses on beliefs that determine behavior. The model incorporates such concepts as (a) the importance of health; (b) personal control of health; (c) perceived self-efficacy; (d) definition of health; (e) perceived health status; (f) perceived benefit of the behavior modification; and $(\mathrm{g})$ perceived barriers to health-promoting behaviors. One of the key components of this model is the belief that anyone, regardless of their level of ability, age, or current health status, can improve their level of function and enjoy what for them is an optimal level of health. Beliefs are of crucial importance when people consider ways to improve their health status. One must first believe that a change can occur in order to attempt to effect such a change. Only when a person believes such a change is possible does a class such as the one utilized in this study serve as a potential tool to implement this change. 


\section{Literature review}

The importance of activity, especially in preventing falls, has been well documented. Both medical and nursing journals have an abundance of literature concerning women as they age. Raab, Agre, McAdam, and Smith (1988) investigated the effects of light resistance exercise and stretching on flexibility in elderly women. This study, conducted over a 25-week period, utilized a control group, an exercise group which eventually incorporated the use of weights for added resistance, and an exercise group which did not use added weight. Findings suggested that exercise can enhance flexibility in older women, and that for some elderly women, greater results for improved flexibility were achieved without adding weights.

Evans and Rosenberg (1991) discussed the effects of aging and used the term sarcopenia to describe a reduction in activity to the point of being completely sedentary but without any specifically diagnosed disease. These authors related this sedentary lifestyle directly to entry into the "disability zone," that place where "physical impairments rule your life" (p. 26).

Topp, Mikesky, and Bawel (1994) found that physiological changes in the composition of muscle in an aging body correlate to actual functional declines. Falls represent a serious health problem for persons over the age of 65 and are the leading cause of death for those over the age of 75 (Mills, 1994). The Mills study focused on the effects of aerobic exercise on sedentary elders. She found that falls were a leading cause of accidental death among persons aged 75 and older and, further, that the mere fear of experiencing another fall caused these fall victims to severely limit their activities. The study concluded that the experimental group improved balance by $22 \%$, although they found little difference between the groups for muscle strength or flexibility. 
Holm (1996) reported research with regard to aging women and noted that $90 \%$ of all hip fractures occur in women over 70 years of age. She also found that costs associated with hip fracture run in the billions of dollars annually, and are associated with extended hospital stays and long term care. Additionally, hip fractures represent the second leading cause of nursing home placements.

Decreasing the incidence of falls in the frail elderly is, one could conclude, not only a matter of significant importance for this group of people, but for our health care system generally. Any method of reducing this burden on society, both in terms of human suffering and economic scope, could be of enormous clinical and fiscal importance.

A number of programs have documented their effectiveness in improving strength, flexibility, and balance in elderly women. Gehlsen and Whaley (1990) showed a direct relationship between strength, balance, and flexibility and the lowered risk of falls for the elderly. This study compared a group with a history of falls with a group without that history. It was suggested that the loss of muscular mass and strength lead to a decrease in stability, which leads to a decrease in mobility, which in turn leads to a decline in both flexibility and balance, thus setting up a higher likelihood of experiencing a fall. Additionally, their study concluded that balance, leg strength, and flexibility may be factors that individually and collectively contribute to increased numbers of falls in the elderly.

Judge et al. (1993) conducted research to measure the effects of exercise in improving balance in elderly women. This study analyzed 21 elderly women with an average age of 68, comparing the effects of two exercise programs on static balance. Results demonstrated "improvements 
in single-stance postural sway in older women with exercise training" ( $p$. 254).

Researchers at the Jean Mayer U.S.D.A. Human Nutrition Research Center on Aging at Tufts University have performed recent studies with regard to strength training. They examined frail elderly men and women, some in their $90 \mathrm{~s}$, who lived in nursing homes. While some of the elderly participants used canes to ambulate, after as little as 8 weeks of lifting weights they not only "dramatically improve[d] their strength, balance, and walking ability ... [but in one study] several of the elderly volunteers were able to give up their canes and walk unassisted" (Women's Health Advocate, 1997, p. 4).

In later clinical studies, the effects of strength training and its relationship to bone mineral density was analyzed. In their book Strong Women Stay Young, Nelson and Wernick (1997) have outlined a method by which women can "replace fat with muscle, reverse bone loss and improve energy and balance" (Nelson \& Wernick, p. 11). The study which provided the material for this book was conducted at Tufts University, School of Nutrition Science and Policy in Boston, Massachusetts and has resulted in a safe, scientifically based program utilizing eight basic exercises which can easily be done in the privacy of one's home twice a week. The results to date have shown improvement not only in a woman's strength, balance, flexibility, and bone density, but also the way she looks to others and to herself. The Nelson and Wernick program provided the basis for this intervention program.

\section{Research Procedure}

This study was quasi-experimental, as there was an intervention (the exercise program) but there was no control group or random assignment. 
The subjects were a convenience sampling of volunteers recruited from a number of senior citizen centers located in an urban area of Northern California. A flyer announced the proposed exercise class and solicited volunteers to participate.

Consent was obtained to allow this program to be conducted on the premises of a city-sponsored senior citizen center and Human Subjects approval was received. The facility offered a large, comfortable, and yet private room in which to conduct this class.

The first 15 volunteers who agreed to participate in the project were given a PAR-Q (Physical Activity Readiness Questionnaire, Rev. 1994) to assist them and their health care providers in evaluating the propriety of their participation in this study (Nelson \& Wernick, pp. 104-105). This instrument measures readiness to participate in a program such as this exercise program. Participants were also provided with consent forms, to be signed by their health care providers and collected by the research investigator at the outset of the program.

At that initial meeting, the purpose and the mechanics of the program were explained to the volunteers. Both the volunteers' consents and the medical consents were collected.

Each participant then completed exercise moves which provided four baseline measurements. Upper arm strength was measured by counting the number of times a biceps curl was performed over a period of 1 minute while holding a 5 pound weight. Leg strength was measured by counting the number of times a seated leg lift was performed over a period of 1 minute with a 10 pound ankle weight in place. Balance was measured by counting the number of seconds a participant could maintain balance while standing on one leg with arms relaxed at her side, and flexibility was measured by the 
number of inches one could bend forward between extended and spread legs while in a seated position.

Perception of arm and leg strength, flexibility, and balance were measured by asking the participants for their narrative comments. They were asked informally to tell the researcher about their balance, strength, and flexibility. No structured instrument was used; the researcher elicited spontaneous comments from the participants on these topics and recorded the comments.

\section{The Exercise Program}

Following this initial measurement, the eight basic exercises which comprise this program were demonstrated (Figure 1). The volunteers participated in a series of stretching warm-up moves followed by the exercises, at first without the use of any weight. Once everyone was comfortable with the basic moves, weights were added beginning with 1 pound hand and ankle weights, gradually increasing over time as individuals tolerated an increase in resistance. Following each exercise session, the stretching moves were repeated.

The exercise group met for 1 hour sessions twice a week for 8 consecutive weeks. At the end of each meeting, a summary of each person's performance for that day was completed. These summaries were used by the participants to gauge their activity level and assist them in moving forward to increased intensity of each individual exercise.

At the end of the 8-week period, each participant's upper and lower extremity strength, balance, and flexibility were measured again utilizing the same tool used to provide the baseline measurements taken at the onset of the program. At this time, a second interview with each participant was conducted to assess perceived changes in balance, flexibility, and extremity 
strength, including how those changes, if any, affected their activities of daily living.

Results

The sample was composed of six women, ranging in age from 69 to 85 ( $M=75.8)$. Pre- and post-test means were computed for upper arm strength, leg strength, trunk flexibility and balance. Changes are shown as percentage improvement of pre-test mean scores. Table 1 illustrates the results.

There was considerable variability in the participants' response to the 8 weeks of weight-bearing exercise. While the majority who completed the study showed improvement in most areas, several participants showed either no change or showed a decreased level of performance in some of the categories. As shown on Table 1, however, improvement was shown in every category, with the greatest improvement $(41.6 \%)$ shown in the area of balance and the least (8.3\%) in trunk flexibility.

By the end of the 8-week exercise period, women who at the outset of the study could not stand on one leg without holding on to the wall for stability for more than 5 seconds were able to double that with ease while standing without support.

The narrative comments provided by the participants concerning their own perceptions of change demonstrated the genuine pleasure and surprise expressed by each of the study's subjects as they slowly became able to perform the exercises, particularly the one leg stands which measured balance, with steadily increasing ease. The participants were to a person quick to remark on their satisfaction with their perceptions of improved strength and balance. They gave as examples the ease with which they were now able to carry groceries, increased distances covered during 
routine walks, and remarks from significant others regarding improved posture and gait. There was a consensus among the participants that they would not only continue the exercises on their own, but would lobby the senior center for future strength training programs.

\section{Discussion}

At the turn of the 20th century, the United States was primarily an agricultural-based society, comprised of many people who spent a large part of their day engaged in manual labor. Death was more often the result of infectious disease than physical inactivity or old age. In the decades since, industrial and medical technology have dramatically changed that scenario.

This study and others like it are useful for health care practitioners to encourage the promotion and expansion of weight-bearing exercise programs in community senior centers, YMCA and YWCAs, and other facilities which provide social and health care to women over the age of 65. The study and its findings may also stimulate further research aimed at guiding the activities of the elderly.

Improving the quality of life of people as they age can also be studied in terms of the fiscal benefit, not only for people individually, but for society generally. With health care costs measured in the billions of dollars, and going up each year, it is appropriate that every potential tool to assist in prolonging good health status be investigated and encouraged. With record numbers of Americans entering their senior years, time is of the essence in accomplishing this goal.

Studies of women in their sixties, seventies, and eighties have shown that muscle strength can be improved, along with balance and flexibility. The practice of utilizing arm and ankle weights while performing eight simple exercises twice a week has shown this to be an attainable goal for women in 
this age group. The potential for subsequent improvement not only in physical well-being, but overall quality of life can only be beneficial to both individuals specifically and society generally.

This study is limited by the group meeting on only two days of the week. During the remaining 5 days, the participants may or may not have continued to perform any or all of the program exercises or other types of exercise. The small number of participants were volunteers and may not provide a representative sample. Results may not be generalized beyond this study. This program should be replicated with a larger sample over a longer prior of time to test its assumptions.

Implications for Nursing Practice

In her paper for Healthy People 2000, entitled Breaking the Silence: a Health Promotion Approach to Osteoporosis, Drugay (1997) states that "(a)s nurses we must be advocates for health promotion and disease prevention strategies that will improve the health of all Americans, even if it is one at a time" (p. 36). The challenge goes beyond the use of prescription medication and nutritional counseling to include issues of safety maintenance and prolonged independence through improved strength, balance, and flexibility in an effort to combat the genetic effects of aging. Drugay suggests that a person's optimum health status is achieved through appropriate diet, exercise, and lifestyle choices, and challenges nurses to see the potentially debilitating consequences of some lifelong habits and lifestyle choices as pediatric practices with geriatric consequences. An appropriate prescription for regular exercise, including the utilization of weights, may be exactly what is needed to foster improved quality of life among elders, enabling them to maintain a high level of safety, independence, and dignity well into their "golden" years. 


\section{References}

Drugay, M. (1997). Breaking the silence: a health promotion approach to osteoporosis. Journal of Gerontological Nursing, 23(6), 36-43.

Evans, W., \& Rosenberg, I.H. (1991). Biomarkers: The 10 keys to prolonging vitality. New York: Fireside.

Gehlsen, G., \& Whaley, M. (1990). Falls in the elderly: Part II, balance, strength, and flexibility. Archives of Physical Medicine and Rehabilitation, 71, 739-741.

Holm, K. (1996). Why women should exercise. Reflections, 3d qtr., 1112.

Jones, J.M., \& Jones, K.D. (1997). Promoting physical activity in the senior years. Journal of Gerontological Nursing, 23, 40-48.

Judge, J., Lindsey, C., Underwood, M., \& Winsemius, D. (1993). Balance improvements in older women: Effects of exercise training. Physical Therapy, 73, 254-264.

Kohrt, W., Snead, D., Slatopolsky, E., \& Birge, S. (1995). Additive effects of we4ight-bearing exercise and estrogen on bone mineral density in older women. Journal of Bone and Mineral Research, 10, 1303-1311.

Mills, E.M. (1994). The effect of low intensity aerobic exercise on muscle strength, flexibility, and balance among sedentary elderly persons. Nursing Research, 43, 207-212.

Nelson, M., \& Wernick, S. (1997). Strong women stay young. New York: Bantam Books.

Pender, N. (1987). Health Promotion in nursing practice. Stamford, CT: Appleton \& Lange. 
Raab, D., Agre, J., McAdam, M., \& Smith, E. (1988). Light resistance and stretching exercise in elderly women: Effect upon flexibility. Archives of Physical Medicine and Rehabilitation, 69, 268-276.

Topp, R., Mikesky, A., \& Bawel, K. (1994). Developing a strength training program for older adults: Planning, programming, and potential outcomes. Rehabilitation Nursing, 19, 266-273.

U.S. Bureau of Census. (1977). Current Population Reports, Special Studies, P23-193. How We're Changing. Washington, D.C.: U.S. Government Printing Office.

U.S. Department of Health and Human Services, Public Health Service. (1995). Healthy People 2000 Review and 1995 Revisions. Washington, D.C.: U.S. Government Printing Office.

Women's Health Advocate. (Oct. 1997). Getting stronger: The secret to aging well? $4-6$. 
Table1

Strength, Flexibility and Balance

Improvement Following an Exercise Program

Mean Score Results

Percentage Improvement

Pre-Test Post Test

Upper Arm

Strength

11.8

16.4

38.9

(\# of repetitions)

Lower Extremity

Strength

16.2

21.0

29.6

(\# of repetitions

Trunk

Flexibility

14.4

15.6

8.3

(\# of inches)

Balance

14.4

20.4

41.6

(\# of seconds) 
Figure Caption

Figure 1. Illustration of each of the exercises performed in this study.
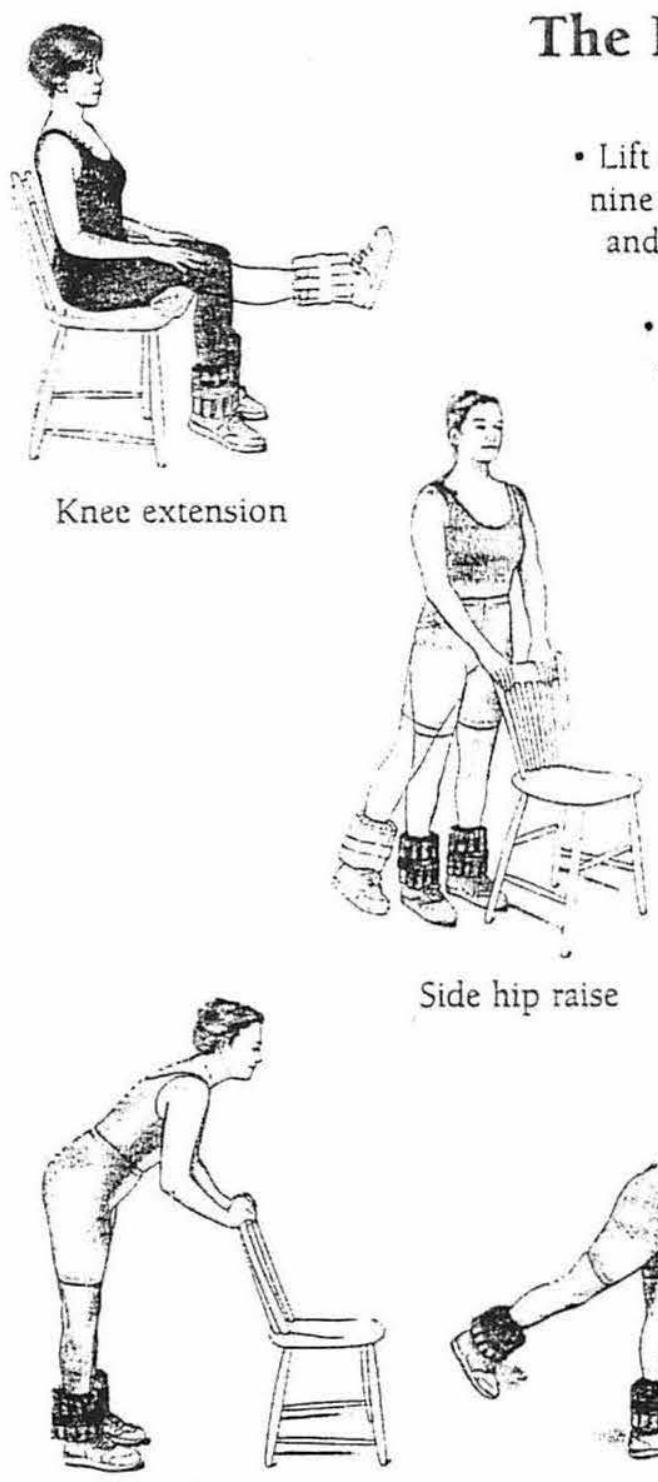

Side hip raise

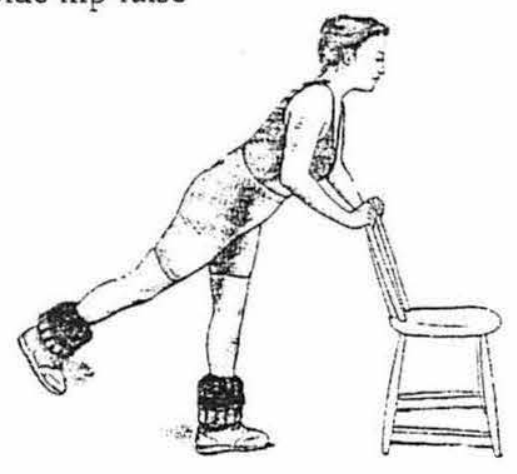

Hip extension

Overhead triceps
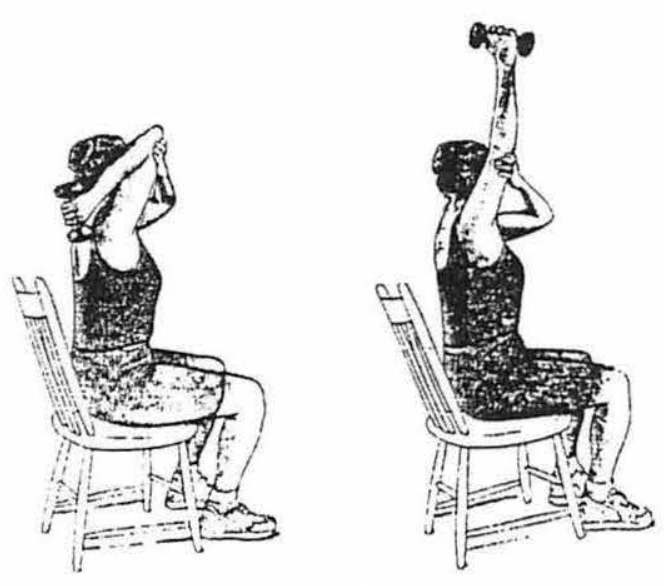

- Lift slowly and smoothly. Each repetition should take about nine seconds-four to lift the weight, a one-second pause, and four to slowly lower the weight. Don't hold your breach!

- Perform each exercise eight times; rest for one to two minutes; then do another set of eight repetitions.

- Choose a weight that's enough to challenge you without being dangerous. (For some women. that will mean performing the exercises without any weights at all.) You should be able to complete the two sets of eight repetitions, but you shouid teel near-maximal effort on the last repetition. When you no longer feel "maxed out" on the last lift, add weight.

- Correct form is essential.

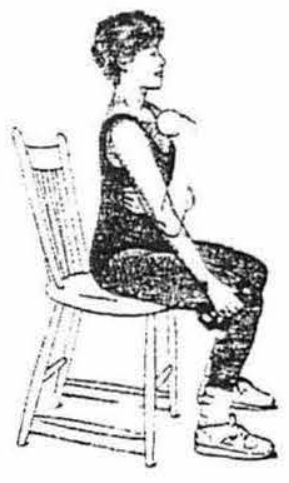

Biceps curl

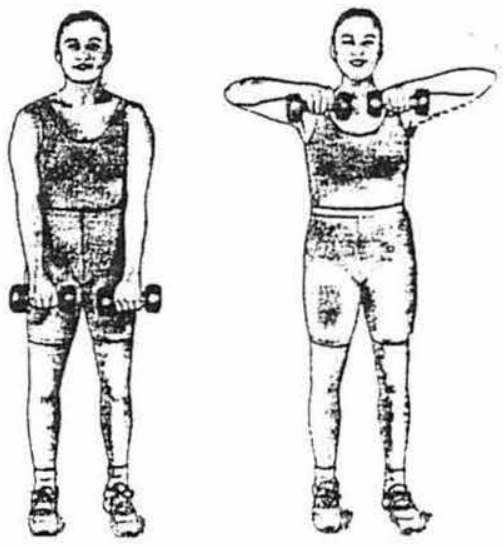

Upward row 


\section{Strength Training $16=\ldots$}

Figure 1.

TOP 